\title{
Methodology for Diagnosing Sensor Faults on Engine Test Benches
}

\author{
Michael Wohlthan ${ }^{1}$, Gerhard Pirker ${ }^{1}$, Andreas Wimmer ${ }^{2}$ \\ ${ }^{1}$ LEC GmbH, Inffeldgasse 19, A-8010 Graz, Austria \\ 2 Graz University of Technology, Institute of Internal Combustion Engines \\ and Thermodynamics, Inffeldgasse 19, A-8010 Graz, Austria \\ michael.wohlthan@lec.tugraz.at
}

Summary: This paper presents a new approach for a diagnostic system that detects and isolates sensor faults at engine test benches. The modular system as well as the combination of physics-based and data-driven modelling concepts allow highly flexible application on various types of engine test benches. The adaptability of the system is validated using measurement data from two different engine test benches.

Keywords: fault diagnosis, engine test bench, model-based diagnosis, sensor faults, adaptable system

\section{Motivation and Objective}

Experimental investigations on engine test benches are a significant cost factor in current combustion engine development. To keep the number of required tests and their associated costs low, it is essential that sensor faults and measurement errors are detected in an early stage [1]. Fritz [2] estimates that up to $40 \%$ of test bench time is lost due to faults that are detected too late. Because of the increasing number of sensors and actuators in combustion engines, reliable validation of test results by one person alone has become nearly impossible. On the whole, there is a need for an automated diagnostic system that evaluates measurement data quality and identifies faulty measurement sensors. The great challenge in applying a diagnostic system at engine test benches is that they are often subject to frequent changes in the test engine. Therefore, the diagnostic system must be able to be adapted easily to different types of test engines.

\section{System Description}

The proposed diagnostic system works according to the procedure shown in Fig. 1. The test bench produces measurement data ( $x$ stands for the measured value of any sensor) which is then checked by a diagnostic procedure consisting of three steps: symptom generation, fault detection and fault isolation. In the symptom generation step, the diagnostic system is adapted to the changeable test engine. This is done by defining limits, formulas (e.g. redundancies or simple physical relations) or by using models.
Modeling is either done online and automatically with data-driven methods [4][5] or initially before the test is started using an engine componentspecific (cylinder, turbocharger, throttle valve, etc.) model library containing physics-based models [6]. Each model, formula or limit check ultimately delivers a residual $r$, which serves as a fault symptom based on the deviation between measurements and model equation-based computations [3].

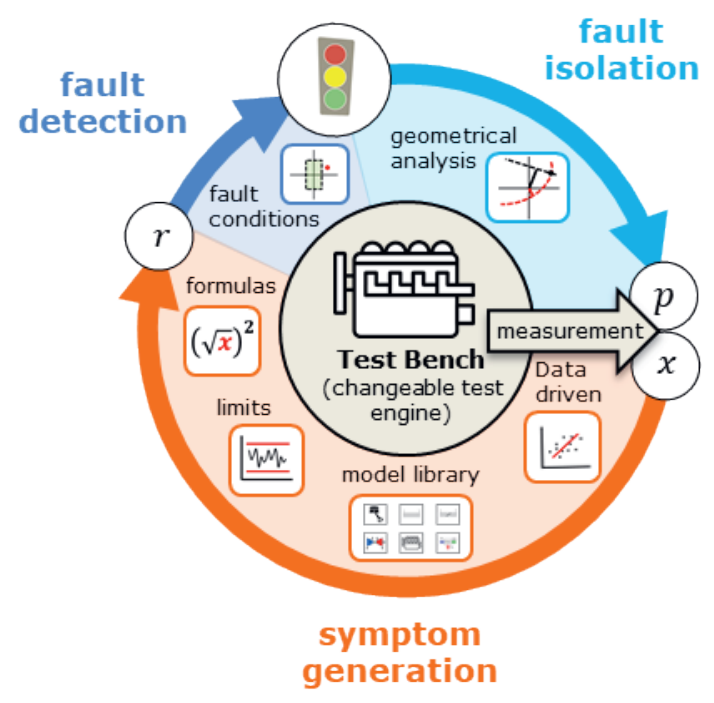

Fig. 1. Scheme of diagnostic procedure

In the second step, fault detection is performed in order to determine whether a fault has occurred in the respective measurement. This is done by checking fault conditions (1).

$|r|>t h r$ 
Thus, a fault is detected if the value of the residual exceeds a certain threshold thr. Finally, it is determined which sensor is faulty. In this third and final step, fault probabilities $p_{i}$ are calculated for all considered sensor values $x_{i}$ using a geometrical classification method based on the distance evaluation between error propagation curves and residual state points [7].

\section{Results}

The following figure shows the diagnostic results of two different test engines. The first engine is a multicylinder diesel engine (layout in Fig. 2, left) and the second a single-cylinder research engine (layout in Fig. 2, right). The diagnostic system is adapted to these engines using different models. This happens either automatically through the online training of data-driven models or by choosing different component-specific modules from the physics-based model library.

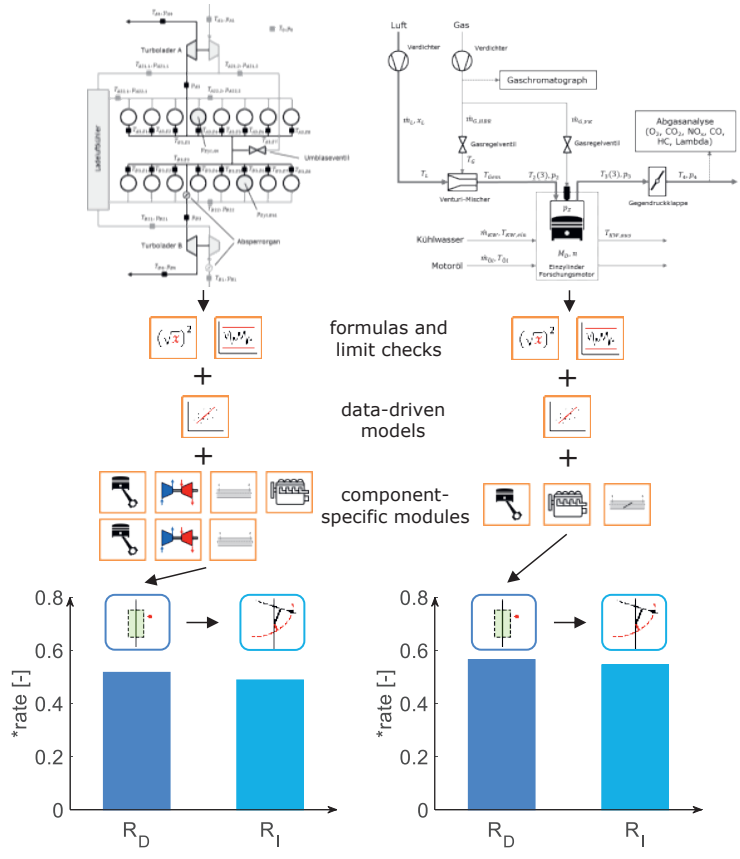

Fig. 2. Comparison of the diagnostic results of a multicylinder diesel engine (left) and a single-cylinder research engine (right)

Evaluation quantities are necessary for an objective validation of the diagnostic system. To evaluate fault detection independently of fault isolation, two quantities are introduced: the detection rate (2) and the isolation rate (3).

$R_{\mathrm{D}}=\frac{\text { number of correctly detected faults }}{\text { number of actual faults }}$

$R_{\mathrm{I}}=\frac{\text { number of correctly isolated faults }}{\text { number of actual faults }}$
Fault-free measurements from real test bed operation provide the initial basis for the analysis. In order to obtain the large number of faulty measurements necessary for the evaluation of the two quantities, abrupt faults with different timings and different intensities are simulated for all implemented sensors. Fault diagnosis is then performed with all measurement data obtained in this way. Finally, the overall detection rate and the overall isolation rate are calculated.

\section{Conclusions}

Two important conclusions can be derived from the results shown in Fig. 2. Despite the great differences between the test engines, comparable diagnostic results are achieved. This shows that the diagnostic system can be used flexibly with different test engines because of its adaptability. At this point, it should also be mentioned that the scope of application is not limited to combustion engines. The modular approach can generally be applied to other test bed systems as well if the corresponding model library has been developed for it. Furthermore, it can be seen in Fig. 2 that in both cases, the isolation rate $R_{\mathrm{I}}$ is only slightly below the detection rate $R_{\mathrm{D}}$, which means that nearly every fault that is detected is also correctly isolated.

\section{References}

[1] A. Flohr, Konzept und Umsetzung einer OnlineMessdatendiagnose an Motorprüfständen. Dissertation, Technische Universität Darmstadt (2005)

[2] S.C. Fritz, Entwicklung und Umsetzung einer zentralisierten Messdatendiagnose für Motorprüfstände als integrierter Bestandteil des Prüstandssystems. Dissertation, Technische Universität Darmstadt (2008)

[3] R. Isermann, P. Balle, Trends in the Application of Model Based Fault Detection and Diagnosis of Technical Processes. Control Engineering Practice, Vol. 5 (1997); doi: 10.1016/S09670661(97)00053-1

[4] D. Schadler, Model based methods for fault diagnostics at engine test beds, ISCCRO18: $2^{\text {nd }}$ International Statistical Conference in Croatia (2018)

[5] D. Schadler, E. Stadlober, Fault detection using selected data and updated regression models, Measurement Vol. 140 (2019); doi: 10.1016/j.measurement.2019.04.010

[6] M. Wohlthan, Methoden zur Fehlerdiagnose an Motorprüfständen, Dissertation, Technische Universität Graz (2019)

[7] M. Wohlthan, D. Schalder, G. Pirker, A. Wimmer, A multi-stage geometric approach for sensor fault isolation on engine test beds, Measurement Vol. 168 (2021); doi: 10.1016/j.measurement.2020.108313 